\title{
Response to dipsogenic stimuli after abdominal vagotomy in rats
}

\author{
JAMES R. MARTIN \\ Institute for Behavioral Science, Swiss Federal Institute of Technology, Zürich CH-8092, Switzerland
}

and

\author{
DONALD NOVIN \\ Psychology Department and Brain Research Institute, University of California \\ Los Angeles, California 90024
}

\begin{abstract}
Following recovery from bilateral subdiaphragmatic vagotomy (including transection of the hepatic branch of the vagus) or sham surgery, rats exhibited osmotically induced drinking during the 24-h posttreatment. However, the vagotomized rats drank less than did the control animals in all measurement intervals. Furthermore, the control rats exhibited osmotically induced drinking following intraperitoneal injection of a much smaller $\mathrm{NaCl}$ load than did the vagotomized rats. Isotonic saline consumption by vagotomized rats was also less than that of control animals after a subcutaneous injection of $10 \%$ polyethylene glycol and $.5,1.0$, and $2.0 \mathrm{~h}$ of access to saline, but was comparable to that of control rats after 3.0 and $24.0 \mathrm{~h}$ of saline access. Despite the use of experimental procedures that minimized stress and debilitory effects, vagotomized rats exhibited less short-term drinking than did control animals following treatment with polyethylene glycol or hypertonic saline. However, although vagotomized rats receiving a $\mathrm{NaCl}$ load continued to drink less than did control rats throughout the 24-h test period, long-term fluid intake by vagotomized and control animals was not different after polyethylene glycol treatment.
\end{abstract}

The results of several investigations have implicated the vagus nerves in contributing to the behavioral control of water and electrolyte balance in the rat. Kraly, Gibbs, and Smith (1975) demonstrated that intracellular dehydration produced by injection of hypertonic saline elicited significantly less drinking by abdominally vagotomized rats than by control animals. Similarly, extracellular dehydration induced with administration of polyethylene glycol was less effective in eliciting water drinking by vagotomized rats, but, when isotonic saline was of fered $24 \mathrm{~h}$ after injection with polyethylene glycol, vagotomized and control rats drank comparable volumes in a 1-h test. It has also been demonstrated that although abdominally vagotomized rats drank less than control rats following injection with hypertonic saline, these denervated rats drank significantly

This research was supported by Grant NS7687 from the National Institute of Neurological and Communicative Disorders and Stroke to D.N. and by National Institutes of Health Postdoctoral Fellowship F32 MH05101 to J.R.M. A preliminary report of this research was presented at the 1977 meeting of the Society for Neuroscience in Anaheim, California. The authors gratefully acknowledge the suggestions and criticisms of K. Baettig, P. J. Geiselman, and R. Buzzi. Requests for reprints should be sent to J. R. Martin, Institut für Verhaltenswissenschaft, ETHZentrum, Turnerstrasse 1, 8092 Zürich, Switzerland. more water following injection with hypertonic saline than after injection of isotonic saline (Martin, Geiselman, \& Novin, 1979). Thus, consistent with previous reports of the involvement of brain osmosensitive cells in modulating drinking (Blass \& Epstein, 1971; Peck \& Novin, 1971), these results emphasize that responsiveness to intracellular dehydration, albeit impaired, survives abdominal vagotomy. However, in apparent contradiction to these findings, Zimmer, Meliza, and Hsiao (1976) reported that abdominal vagotomy did not impair drinking in response to injection of hypertonic saline, whereas the volume of isotonic saline consumed in the 24 h period following polyethylene glycol treatment was actually enhanced in vagotomized rats.

The present study was designed to further investigate these reported impairments in the regulation of drinking by abdominally vagotomized rats. $\mathrm{Nu}$ merous recent investigations have emphasized the importance of the stressfulness of experimental manipulations done to a denervated animal in determining its behavioral responsiveness. In certain circumstances, animals unresponsive to stressful regulatory challenges induced with high doses nonetheless exhibit regulatory capabilities when tested with a lower dose or in a much longer test period (Coburn \& Stricker, 1978; Stricker, 1976; Stricker, Friedman, 
\& Zigmond, 1975). In view of the potentially stressful properties of intraperitoneal administration of hypertonic saline (Giesler \& Liebeskind, 1976), the first experiment evaluated the dipsogenic effect of several concentrations of saline, ranging from isotonic to $.77 \mathrm{M} \mathrm{NaCl}(1 \% \mathrm{BW})$, in abdominally vagotomized and control rats over a 24-h test period. In a second experiment with vagotomized rats, extracellular dehydration was induced with a subcutaneous injection of polyethylene glycol. Following a 6-h interval to permit sequestration of body fluid due to dialysis, isotonic saline was offered and intake was monitored over the subsequent $24 \mathrm{~h}$. To avoid the adverse effects of a long fast, the subjects were permitted continuous access to food throughout both test procedures. However, since no feeding occurred during the initial $.5 \mathrm{~h}$ of fluid access following either hypertonic saline injection or access to saline $6 \mathrm{~h}$ after polyethylene glycol treatment, the elicited drinking during this interval represented responsiveness to the osmotic or the volemic challenge, respectively.

\section{GENERAL SURGERY AND VERIFICATION PROCEDURES}

All surgery was performed with rats anesthetized with sodium pentobarbital $(50 \mathrm{mg} / \mathrm{kg})$. Denervation and sham surgery were carried out under aseptic conditions. Abdominal vagotomy involved bilateral transection of the subdiaphragmatic branches of the vagus, including transection of the hepatic branch of the vagus. This surgical procedure consisted of removal of all connective tissue from the vertex of the stomach for a distance of approximately $15-20 \mathrm{~mm}$ along the proximal esophagus. The hepatic branch of the vagus was located and cut, and then the esophagus was examined for any remaining nerve fibers, which were dissected from the esophagus, with care taken to avoid any unnecessary damage to the esophageal musculature. In order to ensure the transection of the posterior trunk of the vagus as it is described by Legros and Griffith (1969), the left gastric artery and adjacent tissue were ligated and cut. Collateral circulation has been reported to develop rapidly, and any damage to stomach tissue heals long before the start of behavioral testing in the present experiments (Berg, 1947). Sham vagotomy involved gentle manipulation of the esophagus and stomach with forceps. During recovery over a 6-12-week period, the rats received Purina Lab Chow and tap water ad lib, as well as additional palatable foods (as necessary) to prevent loss of body weight. Testing was started after a minimum of 6 weeks and only after stable body weight was maintained for 1 week, during which only ad-lib Purina Lab Chow and tap water were available.

After the conclusion of all behavioral testing, the success of the denervation procedure was evaluated with an electrophysiological technique. Under sodium pentobarbital anesthesia $(50 \mathrm{mg} / \mathrm{kg})$, both cervical vagi were dissected from the common carotid arteries and, together, were placed over two platinum electrodes. The extent of vagal destruction was then assessed in surgically vagotomized and sham-operated rats by electrically stimulating the cervical vagi while monitoring gastric contractions with a balloon inserted into the stomach and attached to a pressure transducer. Additional details concerning this procedure are provided in an earlier paper (Martin, Rogers, Novin, \& VanderWeele, 1977). Vagally intact animals exhibited electrically evoked gastric contractions, whereas those rats that had sustained extensive vagal destruction exhibited no evoked contractions. Sham-vagotomized rats exhibiting evoked gastric contractions were included in the control group (sham). Only those surgically vagotomized rats that exhibited no evoked gastric contractions were included in the experimental group (vagx). In the absence of verification procedures for assessing destruction of afferent vagal fibers, this test of efferent vagal function provides some measure of assurance that destruction of subdiaphragmatic vagal innervation was complete.

\section{EXPERIMENT 1}

\section{Method}

Subjects. Forty-two male Long-Evans pigmented rats, ranging in age from 4-5 months at the time of surgery, were used. The animals were individually housed, and the animal quarters were maintained on a 12:12-h light-dark cycle. Purina Lab Chow and tap water were available continuously throughout the experiment.

Procedure. Following recovery from surgery, the rats were habituated to the injection procedure with several intraperitoneal injections of isotonic and hypertonic saline given over a 1-2-week period. Testing consisted of a daily intraperitoneal injection of $.15, .31, .46, .62$, or $.77 \mathrm{M} \mathrm{NaCl}(1 \% \mathrm{BW})$ administered according to a counterbalanced design. Immediately after injection, each rat was returned to its home cage, and a water bottle with a ballbearing spout was attached to the front of the cage. The behavior of the subjects was observed during the initial $.5 \mathrm{~h}$, and cumulative water intake was measured $.5,2.0,4.0,8.0$, and $24.0 \mathrm{~h}$ postinjection to the nearest $.1 \mathrm{~g}$.

In order to minimize the potentially adverse effect of this 24-h test on the health of the vagally denervated rats, all subjects had access to food throughout this interval. However, consistent with the results of preliminary experiments, rats that were habituated to the injection procedure did not feed during the initial .5-h period when the experimenter was present. On the day of the first test, the injection was given $.5 \mathrm{~h}$ prior to the start of the dark portion of the light-dark cycle. However, because of the time required to end one test and to begin the next, this initial $.5 \mathrm{~h}$ of the drinking test that was done with normal lighting gradually replaced a portion of the night cycle so that, by the end of the sequence of injections, the dark period was reduced by about $.5 \mathrm{~h}$ and the light period was correspondingly increased. The largest $\mathrm{NaCl}$ load selected for this experiment was less than that (.5 M NaCl, 2\% BW, ip) used by Dunn, Brennan, Nelson, and Robertson (1973), who reported a maximal elevation of plasma osmolality in rats 15 min postinjection and only a minor deviation above baseline persisting $1 \mathrm{~h}$ postinjection (when no drinking was permitted). Thus, it was expected that the smaller osmotic loads used in the present experiment, in which drinking was permitted, would readily produce rapid osmotic readjustment via both physiological and behavioral mechanisms. However, daily food intake was monitored, and on the few occasions when a subject appeared to be adversely affected by the salt loading, the animal was given palatable foods for several days, and that injection condition and the remainder of the injection sequence were done subsequently. There appeared to be no cumulative effect of the $\mathrm{NaCl}$ injections over successive days in the denervated rats since .5 -h water intake following injection of $.77 \mathrm{M}$ $\mathrm{NaCl}$ on either of the final 2 days of the injection sequence was comparable to that observed in earlier experiments in which $.77 \mathrm{M}$ $\mathrm{NaCl}$ was injected after a minimum of $48 \mathrm{~h}$ following any earlier injection.

The data from the vagotomized (vagx) and sham-operated rats (sham) that had met appropriate verification criteria were calculated on the basis of grams of water consumed $/ 100 \mathrm{~g} \mathrm{BW}$. Separate ANOVA analyses for repeated measures (e.g., saline concentrations) were made for the five measurement intervals to compare the vagx and sham groups. When overall significance $(p<.05)$ was detected for the repeated measures dimension, subsequent analysis was done to separately evaluate the relative dipsogenic potency of the different $\mathrm{NaCl}$ loads within the sham and 
vagx groups. The Bonferroni $t$ statistic was selected for this latter analysis because it could be applied to such repeated measures data (Miller, 1966; Miller, 1977). All statistical comparisons were based upon nondirectional (two-tailed) $p$ values.

\section{Results}

The sham rats $(\mathrm{N}=15)$ drank significantly more water than did the vagx rats $(\mathrm{N}=17)$ in the $.5 \mathrm{~h}$ $[\mathrm{F}(1,30)=12.8, \mathrm{p}<.01], 2.0 \mathrm{~h}[\mathrm{~F}(1,30)=19.5, \mathrm{p}<.01]$, $4.0 \mathrm{~h}[\mathrm{~F}(1,30)=20.1, \mathrm{p}<.01], 8.0 \mathrm{~h}[\mathrm{~F}(1,30)=17.3$, $\mathrm{p}<.01]$, and $24 \mathrm{~h}[\mathrm{~F}(1,30)=27.1, \mathrm{p}<.01]$ after injection. The effect of the saline injection concentration was significant for the .5-, 2.0-, and 4.0-h measurement intervals (ps $<.01$ ) and for the 8.0-h interval $(\mathrm{p}<.05)$. There was no significant interaction between the saline injection concentration condition and the surgical condition for any of the postinjection intervals. Figure 1 shows the relative quantities of water consumed after saline injection in the sham and vagx groups following each of the five postinjection measurement periods. In the sham group, injection concentrations of $.31 \mathrm{M}(\mathrm{p}<.05), .46 \mathrm{M}$ $(\mathrm{p}<.01), .62 \mathrm{M}(\mathrm{p}<.01)$, and $.77 \mathrm{M} \mathrm{NaCl}(\mathrm{p}<.01)$ elicited significantly greater water intake than did the isotonic saline injection condition $(.15 \mathrm{M} \mathrm{NaCl})$ for the .5-h postinjection interval. For the 2.0-h measurement period, only injections of $.62 \mathrm{M}(\mathrm{p}<.05)$ and $.77 \mathrm{M} \mathrm{NaCl}(\mathrm{p}<.01)$ were significantly more effective than isotonic saline in sham rats. Only .77 M $\mathrm{NaCl}$ induced significantly more drinking than did isotonic saline in sham rats after postinjection intervals of 4.0 and $8.0 \mathrm{~h}$ (ps $<.01$ ). During both the .5 -h $(p<.01)$ and the 2.0-h $(p<.05)$ measurement periods, sham rats drank significantly more water following injection of $.77 \mathrm{M} \mathrm{NaCl}$ than after injection of $.62 \mathrm{M} \mathrm{NaCl}$. In the vagx group, $.77 \mathrm{M}$ $\mathrm{NaCl}$ was significantly more effective in eliciting drinking than was isotonic saline for postinjection intervals of $.5 \mathrm{~h}(\mathrm{p}<.01), 2.0 \mathrm{~h}(\mathrm{p}<.05), 4.0 \mathrm{~h}$ $(\mathrm{p}<.05)$, and $8.0 \mathrm{~h}(\mathrm{p}<.05)$. The mean body weight $( \pm \mathrm{SE})$ of the vagx rats prior to surgery was $274 \pm 14 \mathrm{~g}$, and, at the time of testing, the mean body weight of this group was $336 \pm 12 \mathrm{~g}$; the mean body weight of the sham rats was $240 \pm 9$ and $370 \pm 6 \mathrm{~g}$, respectively.

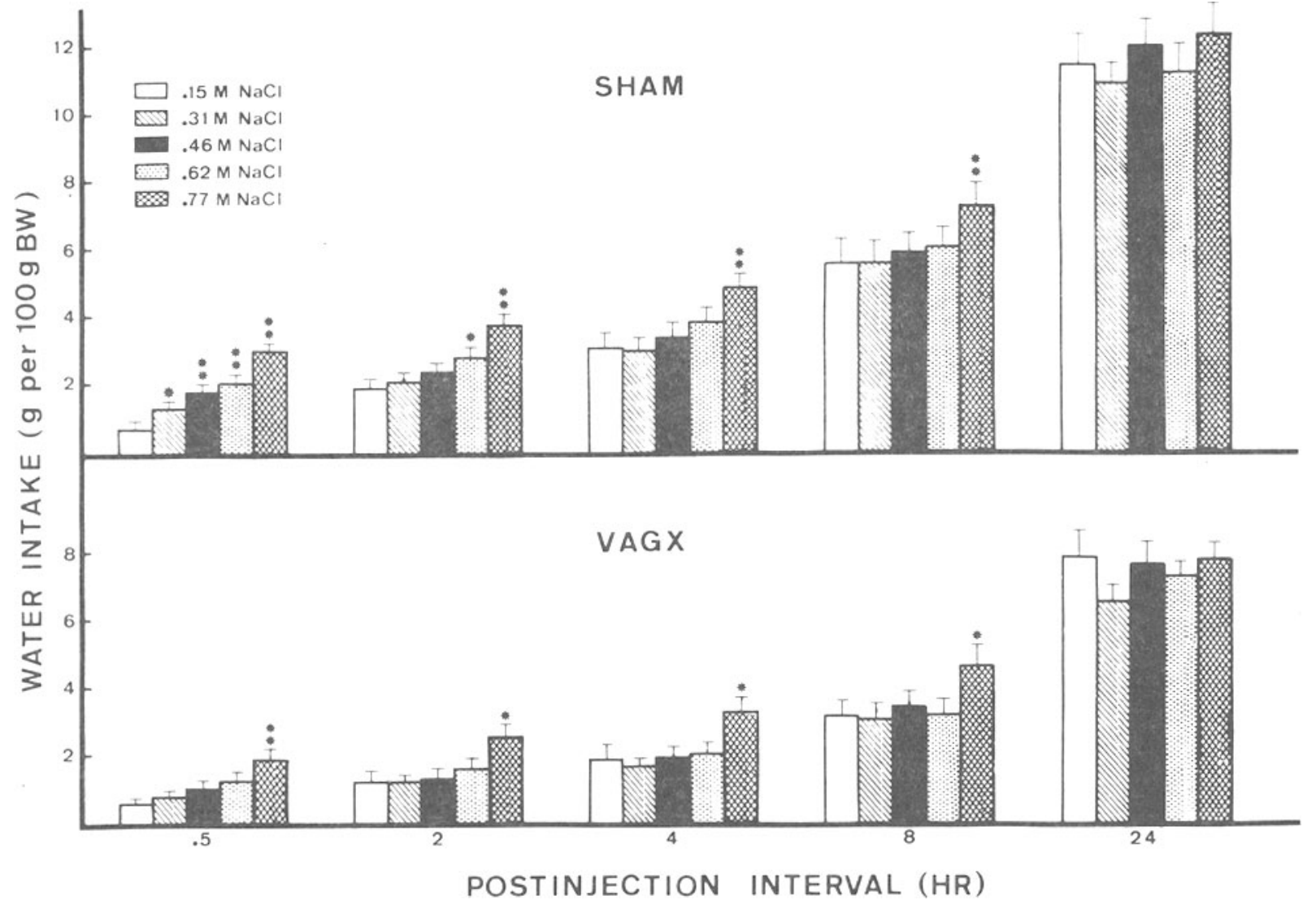

Figure 1. Cumulative water intake of abdominally vagotomized and sham-operated rats following intraperitoneal injection (1\% BW) of several $\mathrm{NaCl}$ concentrations. ${ }^{\star *}(\mathrm{p}<.01)$ and ${ }^{*}(\mathrm{p}<.05)$ indicate a significant difference with the isotonic saline $(.15 \mathrm{M})$ injection condition. 


\section{EXPERIMENT 2}

\section{Method}

Subjects. A total of 32 male Sprague-Dawley rats, ranging from 4-5 months of age at the time of surgery, were used. The animals were housed and maintained as described in Experiment 1.

Procedure. Following recovery from surgery, the vagotomized and sham-operated rats were provided with isotonic saline in addition to their regular diet on several occasions over a 1-2-week period. A single test injection of $10 \%$ polyethylene glycol (average molecular weight 20,000 ), prepared in a $.15-\mathrm{M}-\mathrm{NaCl}$ vehicle, was made $2.0 \mathrm{~h}$ prior to the beginning of the dark portion of the 12:12-h light-dark cycle. Following this subcutaneous injection $(1.5 \% \mathrm{BW})$, animals were denied access to any fluid for $6.0 \mathrm{~h}$, after which a bottle containing isotonic saline was attached to the front of the home cage. Cumulative isotonic saline intake was measured to the nearest $.1 \mathrm{~g}$ at $.5,1.0,2.0,3.0$, and $24.0 \mathrm{~h}$ after its presentation. In addition, the latency to initiate drinking (maximum $30 \mathrm{~min}$ ) was measured by an observer, using red lights. Food was available in the home cage throughout this interval to avoid any debilitating effects of a prolonged fast. However, during the initial $.5 \mathrm{~h}$ of saline access, no feeding occurred due to the large volume of fluid ingested as well as to the presence of the experimenter.

Only data from those sham-operated (sham) and vagotomized rats (vagx) that met their appropriate verification criterion were included in the data analysis. All intake data were calculated on the basis of grams consumed $/ 100 \mathrm{~g} \mathrm{BW}$. Statistical analysis of intake data was done with a nondirectional $t$ test for independent groups to compare the vagx and sham groups. Latency data from the two groups were compared with a nondirectional MannWhitney U test.

\section{Results}

The vagx rats $(\mathrm{N}=14)$ drank significantly less saline than did the sham rats $(\mathrm{N}=12)$ in the $.5 \mathrm{~h}[\mathrm{t}(24)=3.2$, $\mathrm{p}<.05)], 1.0 \mathrm{~h}[\mathrm{t}(24)=2.3, \mathrm{p}<.05]$, and $2.0 \mathrm{~h}$ $[\mathrm{t}(24)=2.8, \mathrm{p}<.05]$ after its presentation. However, saline intake by the two groups was not significantly different 3.0 and $24.0 \mathrm{~h}$ after presentation. Latency to begin drinking was comparable for the vagx $(20 \pm 10 \mathrm{sec})$ and the sham $(23 \pm 11 \mathrm{sec})$ groups. The saline intake data are presented in Figure 2. The

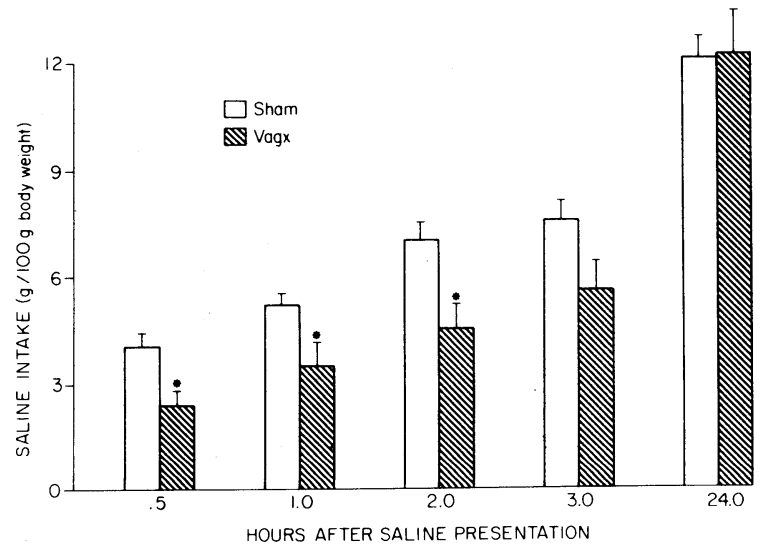

Figure 2. Cumulative isotonic saline consumption of abdominally vagotomized (vagx) and sham-operated (sham) rats following subcutaneous injection $(1.5 \% \mathrm{BW})$ of $10 \%$ polyethylene glycol and a 6.0-h period without fluid access. ${ }^{*}(p<.05)$ indicates a significant difference with the sham group. mean body weight $( \pm S E)$ of the vagx rats prior to surgery was $366 \pm 15 \mathrm{~g}$ and, at the time of testing, it was $438 \pm 27 \mathrm{~g}$; the mean body weights of the sham rats were $370 \pm 7$ and $578 \pm 9 \mathrm{~g}$, respectively.

\section{DISCUSSION}

Recovered subdiaphragmatically vagotomized rats and sham-operated animals exhibited enhanced water drinking during the $24 \mathrm{~h}$ following intraperitoneal injection of a small $\mathrm{NaCl}$ load. However, the threshold $\mathrm{NaCl}$ load necessary to produce osmotic drinking was lower in the sham group. Insofar as feeding was absent from the initial .5 -h period, these results are consistent with those of several earlier reports (Kraly, 1978; Kraly et al., 1975; Martin et al., 1979) that demonstrated a deficit in osmotically induced drinking following bilateral abdominal vagotomy (with or without transection of the hepatic branch of the vagus). The results of Experiment 1 show that vagx rats are responsive to a relatively small osmotic load (.77 M NaCl, 1\% BW). However, this experiment also provides evidence that neither reducing the osmotic load nor extending the measurement interval appreciably alters the weaker drinking response exhibited by vagally denervated rats in comparison with control rats. Extending the test duration to $24 \mathrm{~h}$ resulted only in a gradual diminution of the effect of the salt load, but no evidence of any sizable delayed drinking response to the osmotic load, such as that observed in brain-damaged rats (Coburn \& Stricker, 1978; Grossman \& Grossman, 1978; Stricker, 1976).

In order to minimize the stressfulness of the experimental procedure, access to food was unrestricted. Although feeding was absent from the initial $.5 \mathrm{~h}$ of the test, it did subsequently occur, and thus it is likely that the deficit in food-related drinking reported by Kraly, Smith, and Carty (1978) contributed to the long-term difference in water intake by vagx and sham rats. This deficit in food-related drinking may reflect insensitivity to fluctuations in plasma osmolality or plasma volume. It has previously been noted that an increase in plasma osmolality typically preceded food-related drinking in the rat (Almli \& Gardina, 1974).

The reason for the failure of Zimmer et al. (1976) to observe any impairment in osmotically induced drinking in rats 9 days after bilateral subdiaphragmatic vagotomy is not clear. Snowdon and Wampler (1979) found that osmotically induced drinking by abdominally vagotomized rats was nonsignificantly less than that by controls $.5 \mathrm{~h}$ postinjection and significantly less than that by controls $2.0 \mathrm{~h}$ postinjection. Anika, Houpt, and Houpt (1979) have recently reported that, although subdiaphragmatically vagotomized rats exhibited a deficit in osmotically elicited drinking 2 months after denervation, vagotomized and control rats drank comparable amounts 
of water in response to osmotic challenge 4 months after the surgery. In contrast, Kraly (1978) observed a deficit in osmotically induced drinking 2 and 6 months after subdiaphragmatic vagotomy. Most of the rats in the present investigation, as well as those in an earlier study (Martin et al., 1979), were tested 3 or more months after bilateral abdominal vagotomy, and, at that time, a clear deficit in osmotically elicited drinking was observed. Kraly (1978) also noted that abdominally vagotomized rats with open gastric fistulas drank as much water as did control rats following osmotic challenge. Although these data emphasize the potentially important role of abnormal gastric emptying in accounting for some of the effects of vagotomy on drinking, they fail to adequately account for the longer latency of vagotomized animals to initiate drinking following an injection of hypertonic saline (Kraly, 1978; Martin et al., 1979) or the reported recovery of normal osmotically induced drinking in the absence of any evidence of recovery of efferent vagal function (Anika et al., 1979).

The results of Experiment 2 demonstrated that, following polyethylene glycol treatment and a 6-h delay, 24-h isotonic saline intake by vagx rats was comparable to that of sham rats (although these rats continued to have access to food throughout the test to avoid the adverse effects of a long fast). It is possible that, in the absence of food-thus eliminating any effects of differential food-related drinkingvagx rats would drink more in this 24 -h period than would sham rats, consistent with the observation of Zimmer et al. (1976). The present study also provided evidence that, following polyethylene glycol treatment, vagx rats drink less isotonic saline in the initial $2.0 \mathrm{~h}$ of fluid access than do sham rats, but, after $3.0 \mathrm{~h}$ or more, the isotonic saline intake of the two groups is not significantly different. Zimmer et al. (1976) also noted that isotonic saline consumption was comparable in vagotomized and control rats treated with polyethylene glycol 3.5 and $8.0 \mathrm{~h}$ after presentation. Although latency to initiate drinking of isotonic saline was found to be comparable in vagx and sham rats, the polyethylene glycol treatment procedure resulted in a strong drinking response, and this may have obscured differences between the groups. Alternatively, abnormalities in gastric emptying may have contributed to the short-term deficit in saline consumption observed in vagx rats treated with polyethylene glycol, but had no effect on latency. However, vagotomized rats have been reported to drink very large amounts of isotonic saline $(38 \mathrm{ml})$ in a 1.0-h test given $24 \mathrm{~h}$ after an injection of polyethylene glycol (Kraly et al., 1975). In sum, although 24-h water intake following osmotic challenge is less in vagotomized rats than in control rats (Experiment 1; Kraly et al., 1975), 24-h isotonic saline intake following polyethylene glycol treatment has been found to be comparable in the two groups (Experiment 2) or greater in vagotomized rats (Zimmer et al., 1976). However, vagotomized rats exhibited a deficit in fluid consumption in the initial period of fluid access following polyethylene glycol treatment or hypertonic saline injection. In contrast with the longer latencies of vagotomized rats, as compared with control rats, to initiate osmotically induced drinking (Kraly, 1978; Martin et al., 1979), no difference in latency between vagx and sham rats was observed when access to isotonic saline was permitted 6.0-h after injection of polyethylene glycol.

Treatment with high-molecular-weight polyethylene glycol has been reported to induce weak and transient hyperosmolality (Almli, 1971). This effect might parsimoniously account for the deficit in polyethylene glycol-induced saline drinking observed in the shorter measurement intervals on the basis of loss of input from vagally mediated osmosensitive cells located in the viscera. However, such transient hyperosmolality has not been observed in a subsequent study (Tang, 1976), and, furthermore, the 6.0-h delay prior to presentation of the isotonic saline in the present experiment would preclude all but prolonged hyperosmolality from influencing fluid intake. The absence of feeding during the initial $.5 \mathrm{~h}$ of fluid access (during which approximately one-fourth of the total 24-h intake was ingested) precludes any involvement of food-related factors in this shortterm deficit observed in the vagx group. It is also possible that the short-term deficit in drinking in response to volemic challenge resulted from the inability of the vagx rats to respond rapidly to a strong regulatory challenge, but whether latency to drink fluid $6 \mathrm{~h}$ posttreatment is really an index of acute responsiveness is questionable.

The result of the present investigation, together with those of earlier reports, emphasizes the similarities of abdominally vagotomized rats and those that have sustained brain damage, particularly damage restricted to the rostromedial zona incerta. Both vagotomy and zona incerta lesions result in chronic hypodipsia, decreased water consumption during fasting, attenuated drinking following water deprivation, reduced responsiveness to experimentally induced hyperosmolality, and reduced fluid intake (in some, but not all, cases) following polyethylene glycol treatment (Grossman \& Grossman, 1978; Kraly, 1978; Kraly et al., 1975; Martin et al., 1979; Walsh \& Grossman, 1978). The degree to which the behavioral similarities described result from damage to a common neural substrate has yet to be determined; however, there is anatomical evidence in rat that vagal fibers project to the region of the thalamic ventrobasal complex and dorsal to the zona incerta (Norgren \& Leonard, 1973). Furthermore, it has recently been demonstrated that the activity of numerous cells located in the ventrobasal thalamus is 
inhibited by increases in plasma osmolality restricted to the hepatic-portal vein (Rogers, Novin, \& Butcher, 1979).

Bilateral subdiaphragmatic vagotomy in rat does produce a number of visceral effects that could potentially contribute indirectly to the impairment in drinking. In particular, it appears likely that the reduction in the volume of fluid consumed by abdominally vagotomized rats after osmotic or volemic challenge is partly or wholly the result of alterations in gastrointestinal function. However, the increased latency to drink after osmotic challenge is not so readily explained by such deficits. It is possible that this latency effect is the result of destruction of a visceral osmosensitive system that transmits afferent information to the brain.

\section{REFERENCES}

AlmuI, C. R. Hypervolemia at the polyethylene glycol induced onset of drinking. Physiology \& Behavior, 1971, 7, 369-373.

Almli, C. R., \& Gardina, J. Ad libitum drinking of rats and vascular osmolality changes. Physiology \& Behavior, 1974, 12, 231-238.

Anika, S. M., Houpt, T. R., \& Houpt, K. A. Recovery from disordered drinking by vagotomized rats. Physiology \& Behavior, 1979, 22, 605-608.

BERG, B. N. Gastric ulcers produced experimentally by vascular ligation. Surgical Forum, 1947, 54, 58-66.

Blass, E. M., \& Epste in, A. N. A lateral preoptic osmosensitive zone for thirst in the rat. Journal of Comparative and Physiological Psychology, 1971, 76, 378-394.

Coburn, P. C., \& Stricker, E. M. Osmoregulatory thirst in rats after lateral preoptic lesions. Journal of Comparative and Physiological Psychology, 1978, 92, 350-361.

Dunn, R. L., Brennan, T. J., Nelson, A. E., \& Robertson, G. L. The role of blood osmolality and volume in regulating vasopressin secretion in the rat. Journal of Clinical Investigation, 1973, 52, 3212-3219.

Giesler, G. J., JR., \& Liebeskind, J. C. Inhibition of visceral pain by electrical stimulation of the periaqueductal gray matter. Pain, 1976, 2, 43-48.

Grossman, S. P., \& Grossman, L. Parametric study of the regulatory capabilities of rats with rostromedial zona incerta lesions: Responsiveness to hypertonic saline and polyethylene glycol. Physiology \& Behavior, 1978, 21, 431-440.

KraLY, F. S. Abdominal vagotomy inhibits osmotically induced drinking in the rat. Journal of Comparative and Physiological Psychology, 1978, 92, 999-1013.
Kraly, F. S., Gibrs, J., \& Smith, G. P. Disordered drinking after abdominal vagotomy in rats. Nature, 1975, 258, 226-228.

Kraly, F. S., Smith, G. P., \& Carty, W. J. Abdominal vagotomy disrupts food-related drinking in the rat. Journal of Comparative and Physiological Psychology, 1978, 92, 196-203.

Legros, G., \& Griffith, C. A. The abdominal vagal system in rats: An anatomical study with emphasis upon the distribution of gastric vagi to the stomach. Journal of Surgical Research, $1969,9,183-186$.

Martin, J. R., Geiselman, P. J., \& Novin, D. Drinking to intracellular dehydration following vagotomy in rats. Physiology \& Behavior, 1979, 23, 527-537.

Martin, J. R., Rogers, R. C., Novin, D., \& VanderWeele, D. A. Excessive gastric retention by vagotomized rats and rabbits given a solid diet. Bulletin of the Psychonomic Society, 1977, 10, 291-294.

Mille R, R. G., JR. Simultaneous statistical inference. New York: McGraw-Hill, 1966.

Mille R, R. G., JR. Developments in multiple comparisons, 19661976. Journal of the American Statistical Association, 1977, 72, 779-788.

Norgren, R., \& Leonard, C. M. Ascending central gustatory pathways. Journal of Comparative Neurology, 1973, 150, 217-237.

PECK, J. W., \& Novin, D. Evidence that osmoreceptors mediating drinking in rabbits are in the lateral preoptic area. Journal of Comparative and Physiological Psychology, 1971, 74, 134-147.

Rogers, R. C., Novin, D., \& Butcher, L. L. Hepatic sodium and osmoreceptors activate neurons in the ventrobasal thalamus. Brain Research, 1979, 168, 398-403.

Snowdon, C. T., \& Wample R, R. S. Weight and regulatory deficits in vagotomized rats: A reexamination. Behavioral and Neural Biology, 1979, 26, 342-353.

Stricker, E. M. Drinking by rats after lateral hypothalamic lesions: A new look at the lateral hypothalamic syndrome. Journal of Comparative and Physiological Psychology, 1976, 90, 127-143.

Stricker, E. M., Friedman, M. I., \& Zigmond, M. J. Glucoregulatory feeding by rats after intraventricular 6-hydroxydopamine or lateral hypothalamic lesions. Science, 1975, 189, 895-897.

TANG, M. Dependence of polyethylene glycol-induced dipsogenesis on intravascular fluid volume depletion. Physiology \& Behavior, 1976, 17, 811-816.

Walsh, L. L., \& Grossman, S. P. Dissociation of responses to extracellular thirst stimuli following zona incerta lesions. Physiology \& Behavior, 1978, 8, 409-415.

Zimmer, L. J., Meliza, L., \& Hsiao, S. Effects of cervical and subdiaphragmatic vagotomy on osmotic and volemic thirst. Physiology \& Behavior, 1976, 16, 665-670.

(Received for publication June 1, 1979; revision accepted November 26, 1980.) 